\title{
Performance of a fish pass for multiple species: Scale model investigation.
}

\author{
Didier Bousmar ${ }^{1, *}$, Estelle Courtois ${ }^{2}$, Loïc Van Audenhaege ${ }^{3}$, and Xavier Rollin ${ }^{4}$ \\ ${ }^{1}$ Service Public de Wallonie, Hydraulic Research Laboratory, 6200 Châtelet, Belgium \\ ${ }^{2}$ Université catholique de Louvain, Civil and Environmental Eng., 1348 LLN, Belgium \\ ${ }^{3}$ Université catholique de Louvain, Earth and Life Institute, 1348 LLN, Belgium \\ ${ }^{4}$ Service Public de Wallonie, Nature and Forests Department, 5100 Namur, Belgium
}

\begin{abstract}
Artificial fish passes are often the most effective solution to restore the ecological continuity of a dammed river. Such a pass can be built for specifically targeted fish species, based on the existing knowledge on its swimming capacity and behaviour. Usually, a wider range of possible species are present in the river and may use the fish pass. In the present study, a vertical slot fish pass has been designed for salmonid fish (namely Atlantic salmon Salmo Salar). This fish pass layout was initially tested using a scale model where juvenile fish were introduced. The study has now been extended to other species, some of them having weaker swimming capacity: bleak (Alburnus alburnus); chub (Squalius cephalus); and bullhead (Cottus gobio). Fish behaviour in the pass was observed using PIT-tag and video. PIT-tag tracking enabled to characterise the capability of the fish to cross the whole fish pass. Video recording was used to analyse in more details the behaviour of the fish in a specific pool.
\end{abstract}

\section{Introduction}

Man-made structures like weirs or dams hinder fish displacement along a river. This impacts severely the population of diadromous fish, whose long range migration may be blocked. Non-migratory fish are also impacted as their habitat is split. Building fish passes is often the preferred solution to restore the ecological continuity of the river. Many design options exist from the nature-like bypass channel to the concrete pool pass [1]. Design guidance can be found in the literature $[1,2,3]$. In most cases, the hydraulic design of the pass is intended to fit the swimming capacity and behaviour of a target fish species. The ability of the other fish species present in the river to cross the fish pass is then to be questioned. Some fish pass designs are known to accommodate multiple species, but this capability has seldom been investigated.

The present study focuses on vertical slot fish passes. In the framework of the retrofitting of 7 fish passes on the River Meuse in Belgium, this type of fish pass was selected, notably for space constraints. A physical model of the full pass at scale 1:5 was built to investigate some specific hydraulic aspects [4]. Taking benefit of the existence of this

\footnotetext{
*Corresponding author: didier.bousmar@spw.wallonie.be
} 
model, some tentative experiments were done with living salmonid fish [5]. These experiments demonstrated the ability of juvenile salmonid fish to cross the fish pass.

These experiments have now been extended to other fish species, some of them with weaker swimming capacity: bleak (Alburnus alburnus); chub (Squalius cephalus); and bullhead (Cottus gobio). After a focused state-of-the-art review and a presentation of the Meuse River fish pass project, this paper will present the experimental set-up and the instrumentation used, and will summarize the main observations and findings.

\section{State-of-the-art}

The design of fish passes has been investigated for a long time and many publications provide guidance on this topic [e.g. 1, 2, 3]. In some cases, the actual behaviour of fish in the pass has been tested either in-situ, either in the laboratory. Compared to prototype, laboratory experiments offer a better control of the observations conditions, flow parameters, and fish availability. On the other hand, the fish behaviour can be affected by the artificial environment of a laboratory. In some cases, large scale facilities are available and tests can be done at scale 1:1 [e.g. 6]. In other cases, tests have to be done at a lower scale due to experimental constraints or fish availability. This brief state-of-the-art review focuses on such tests and on the authors' conclusion regarding their range of validity.

Guiny et al. [7] used juvenile Atlantic salmon in a systematic comparison of different types of artificial fish passes. Batches of 20 parrs were introduced in the downstream pool and were observed for 40 minutes. Along with the rate of success in crossing the pass, their trajectories were recorded. These trajectories demonstrated a behaviour strategy that minimize the energy expenditure and optimise the use of cover, by swimming along the walls and close to the bottom. The authors estimated that behaviour of adult salmon should be similar as such strategy is expected to be common among many species.

Quite similar experiments were done by Wang et al. [8] and Cornu et al. [9] using either small chub, either brown trout juvenile (Salmo trutta) in models at scale 1:2.5 to 1:6. Swimming paths and resting area were correlated with the flow pattern. The swimming capacity of fish was related to the velocity in the model, but the use of juvenile fish was not specifically discussed.

The use of juvenile fish as a substitute for adults was specifically addressed by Kynard et al. [10]. Their study focused on lake sturgeon (Acipenser fulvescens). Using adults was not an option due to (1) limited size of available facilities; (2) scarcity of adults and constraints linked to the use of protected species; and (3) limited time slot with migratory adults availability. Assuming that juveniles and adults share similar innate habitat preference, Kynard et al. suggested that the type of structures and swimming mode preferred by juveniles should also be acceptable to adults.

\section{Meuse River fish passes}

A large program has been initiated in Belgium to enable the return of the Atlantic salmon and other migratory species in the River Meuse. This program, called "Meuse Saumon 2000" includes: (1) the building or retro-fitting of fish passes; (2) the restoration of habitats; and (3) the massive reintroduction of salmon eggs and parrs.

Notably, a group of seven fish passes have to be upgraded on the River Meuse, upstream of Namur. These passes were built in the 1980's along new weirs. It appears now that they offer poor performance for large fish species due to: (1) too low total discharge for an effective fish attraction; (2) too small size of their pools for large fish [11]. Additionally, the implantation of new hydropower stations will modify the flow downstream the weir, and the entrance of the passes has to be moved downstream $[4,12]$. 
Due to limited length and width available for rebuilding each fish pass, the only choice was an artificial pass. A vertical slot fish pass type was selected for its polyvalence in terms of target species, but also as positive experience with this type of pass had already been gained on other locations on the Meuse River. The hydraulic design criteria are summarized in Table 1, based on [3]. Atlantic salmon was taken as target species to fix the minimum size, while weaker swimmers were considered for maximum velocity and power dissipation.

The resulting layout is sketched on Figure 1 [12]. The pass consists of 7 slots and 6 pools. Slots are $0.30 \mathrm{~m}$ wide. Pools P1, P2 and P3 have a standard geometry, $3 \mathrm{~m}$ wide and $4.2 \mathrm{~m}$ long. Pools P4, P5 and P6 have a non-standard geometry but with similar volume, as being rebuilt in the existing pass. An additional discharge is conveyed downstream through a culvert located partly under the pools, in order to get the appropriate total attraction discharge. The building of a scale model for detailed investigations was justified by: (1) The complexity of the flow in the non-standard pools and in the attraction channel; and (2) The number of passes to be retro-fitted. Taking benefit of its existence, it was then decided to initiate this exploratory program of tests with living fish.

Table 1. Design criteria for the river Meuse fish passes modernization.

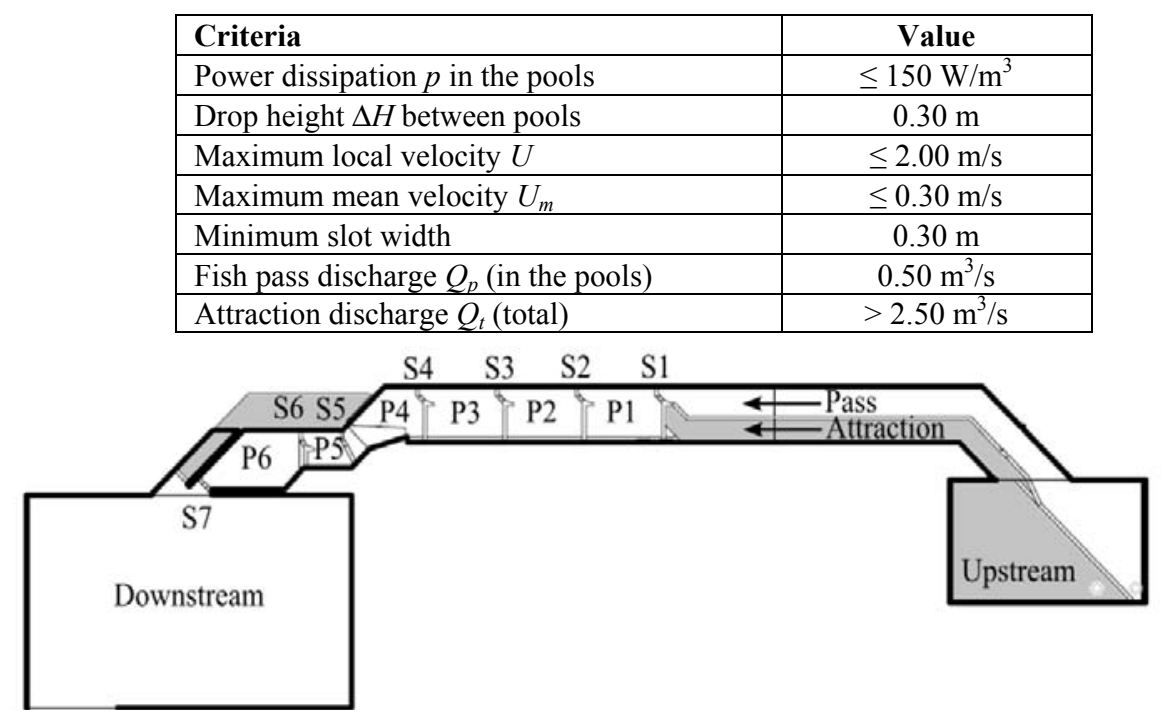

Fig. 1. Fish pass layout (scale model version: P5 is shortened compared to prototype).

\section{Experiments procedure}

A first methodological objective of this study was to investigate the use of living material in a physical model. As pointed out in the state-of-the-art review, laboratory conditions enable easier observations, in a controlled environment. On the other hand, the behaviour of fish may be affected by the artificial environment, and by the limited area of the pass covered by the model. This is particularly the case when the fish is introduced in the downstream pool of the pass: he has no other way to move than crossing the fish pass. In this way, the capability of the fish to cross the fish pass can be assessed. The attraction of the pass can only be tested when the whole pass is modelled including its entrance, although the weir discharge usually cannot be modelled.

An additional bias may arise when the physical model is scaled. The Froude laws of similarity enable proper scaling of discharge and velocity as a function of the geometrical 
scale (here fixed at $\lambda=1: 5$ ). The only option to respect the geometrical scale when using living fish of a given species is using juvenile fish. However, the swimming capacity of the fish does not scale with its size according to Froude similitude. It depends on multiple additional factors: mass, morphology, slow and fast muscle ratio, etc. Based on some literature [13], it can be shown that for a subcarangiform swim the fish burst velocity is proportional to its length $L$ to the power 0.67 ; and its sustained swimming velocity is proportional to its length $L$ to the power 0.56 . As the flow velocity scale with the geometrical scale $\lambda$ to the power 0.50 ; the juvenile fish swimming capacity in the model will actually be lower relative to the adult fish swimming capacity in the prototype.

Taking into account the possible bias linked to the scaling, further objectives of this study were: (1) Estimate the capacity of different (juvenile) fish species to cross successive pools of the fish pass; (2) Test their capacity to enter the fish pass from the downstream river reach; and (3) Observe their swimming behaviour in a characteristic pool.

\subsection{Living material}

Four fish species were selected for the experiments, on the basis of their swimming capacities and their availability [14]. Some general characteristics of these species and of the specific batches used in the experiments are summarized in Table 2. Atlantic salmon was selected as a very good swimmer. It was also successfully used in previous experiments in the same setup [5]. Bleak and chub are also good swimmers, while bullhead is considered to be a weak swimmer. The latter is a benthic fish without swim bladder that swims in a succession of jumps.

Atlantic salmons and chubs were farm fish of wild parents; while bleaks and bullhead were captured in nature. Farm fish were juveniles, selected so that their size approximately corresponds to adult size scaled according to the model geometrical scale. Captured fish were a mix of juveniles and adults, so that the geometrical scale was not more respected.

Table 2. Characteristics of the fish and experiments.

\begin{tabular}{|l|c|c|c|c|}
\hline Fish & $\begin{array}{c}\text { Atlantic salmon } \\
\text { (Salmo salar) }\end{array}$ & $\begin{array}{c}\text { Bleak (Alburnus } \\
\text { alburnus) }\end{array}$ & $\begin{array}{c}\text { Chub (Squalius } \\
\text { cephalus) }\end{array}$ & $\begin{array}{c}\text { Bullhead } \\
\text { (Cottus gobio) }\end{array}$ \\
\hline Living area & Pelagic & Pelagic & Pelagic & Benthic \\
\hline Usual adult length & $750 \mathrm{~mm}$ & $150 \mathrm{~mm}$ & $450 \mathrm{~mm}$ & $100 \mathrm{~mm}$ \\
\hline Length in model & $85 . .105 \mathrm{~mm}$ & $53 . .87 \mathrm{~mm}$ & $59 . .102 \mathrm{~mm}$ & $39 . .112 \mathrm{~mm}$ \\
\hline \# fish & 20 & $45+18$ & $5 \times 20+1 \times 18$ & $4 \times 20$ \\
\hline Origin & Farm & Nature & Farm & Nature \\
\hline Batch duration & $20 \mathrm{~h}$ & $3 \mathrm{~h}$ & $23 \mathrm{~h}$ & $23 \mathrm{~h}$ \\
\hline Observations & PIT-tags & Video & Tags + video & (Tags) + video \\
\hline Introduction & P6 & P6 & P6 + downstr. & P6 (+ P2) \\
\hline
\end{tabular}

\subsection{Observation equipment and procedures}

Fish movements in the fish pass model were monitored using both PIT-tags and video cameras. As summarized in Table 2, large individuals were marked with PIT-tags (12 mmlong HDX ISO tags from Oregon): all salmons, chubs, and only the largest bullheads. Four detection antennas were placed in slots S1, S2, S5 and S6 (see Figure 1). Fish were introduced in the first pool of the pass (P6) and observed for almost one day and night cycle. The records enabled to identify the number of fish who succeeded in crossing the whole fish pass and the time taken. Smaller fish (bleaks and bullheads) were observed and counted visually. 
An additional test was done with the chubs to test the attraction of the pass, introducing them in the river basin, downstream of the fish pass. This test lasted 4.5 days. For this test, antennas were moved to slots S6 and S7, and at the entrance of the attraction channel.

Video cameras were set around the last pools P1 and P2, whose geometry is standard, to observe fish trajectories and preferential presence areas. One camera was side-looking at the level of the slot S2, while two were down-looking above each pool. In order to have a better optical access, Perspex plates were set on the free surface to minimise perturbations due to refraction. A variable amount of air bubbles was nevertheless captured under these plates. Videos were collected during daylight conditions for the bleaks and chubs. As the rate of crossing by the bullheads was insignificant, some additional video recordings were collected by introducing them directly in pool $\mathrm{P} 1$.

Video images were post-processed using the open source software ImageJ: (1) a reference image without fish is subtracted from the black-and-white image to be analysed to highlight the presence of the fish; (2) after filtering, the contours of the resulting patches are identified using a threshold test; (3) location, size and shape of the identified patches are determined; and (4) non-relevant patches corresponding to air bubbles are eliminated, based on their size and shape and on the coherence of trajectories.

\section{Results}

\subsection{Rate of success}

As a first global result, Table 3 gives the rate of total crossing. This rate expresses the number of fish from the batch who crossed the whole pass from slot S6 to slot S1 at least once during the experiment. This global rate has to be analysed carefully, considering all additional information collected.

For the salmon, a much larger rate of partial crossing was recorded, with a value of $78 \%$. This rate corresponds to fish crossing slot S6, and possibly S5 and S2, but not S1. As in the previous experiments [5], fish tend to stay distributed along the whole pass length and show some territorial behaviour: when a fish comes into a pool, this immediately initiates further movements and a redistribution of the fish already presents. As no escape path was available to upstream, this ends up to some immobility of the whole population and possibly to a reduced rate of total crossing. On the other hand, salmon were found at ease within the flow and crossed any slot easily. The duration of the fastest total crossing observed is 6 min (Table 3). The average crossing time is much larger, as some individual stayed $1.5,3.5$ or even 10.5 hours in the pass before crossing slot $\mathrm{S} 1$.

For the bleak, the lower rate of total crossing has to be related to the stress of the fish. The latter were indeed captured fortuitously in a fish pass. They remained in captivity for almost 3 weeks before the experiments. During the tests, the presence of the observer could also affect their behaviour. As a consequence of the need for visual observation, the test duration was also reduced to 3 hours. Nevertheless, most of the crossings were observed during the first 90 minutes. Regarding the fish behaviour, bleaks were found to swim mainly in shoal. They were found at ease in the flow. Only some individuals left the shoal and attempted a crossing. The minimum crossing time for these was $10 \mathrm{~min}$, indicating that the individuals could cross the pass easily.

For the chub, high rates of total crossing from 60 to $85 \%$ were observed for the 6 successive batches, with an average value of $75 \%$. The minimum crossing time was as low as $2 \mathrm{~min}$. The records show that the chub were at ease in the pass and demonstrated large mobility: $50 \%$ of them crossed the whole pass twice or more; and one individual even crossed the pass 13 times during the test. 
For the bullhead, some large individuals were observed crossing one or two slots, but no one crossed the whole pass. Clearly, the observations showed that their swimming capacity was too low to move fluently in the pass, mainly for the small individuals. As it will be illustrated in the next paragraph, most of them could not stabilize their position in the main flow. Bullhead is a benthic fish. The absence of bed roughness elements in the model jeopardised its swimming possibilities and could explain these poor results.

The influence of further factors was investigated through a more detailed analysis of the chub records, as this was the largest database available. At first, a possible "learning" factor was evaluated, by comparing the crossing duration between successive travels for the individuals who crossed the pass several times. Figure 2a shows a progressive reduction of this duration. However, no statistically significant dependence could be highlighted. A partial explanation for this reduction is simply that the individual who took more time for the first crossings didn't have time for further crossing during the overall duration of the test. Figure $2 \mathrm{~b}$ indicates the distribution of crossings with time and photoperiod. Around $2 / 3$ of the crossings occur during the night, with a larger concentration in the beginning of the night time. Lastly, the link between rate of crossing, crossing duration and fish length was investigated. No dependency could be identified.

Table 3. Experimental results for the crossing of the pass (S6 to S1).

\begin{tabular}{|l|c|c|c|c|}
\hline Fish & Salmon & Bleak & Chub & Bullhead \\
\hline Rate of total crossing & $30 \%$ & $14 \%$ & $75 \%$ & $0 \%$ \\
\hline Min. crossing time & $6 \mathrm{~min}$ & $10 \mathrm{~min}$ & $2 \mathrm{~min}$ & - \\
\hline Average crossing time & $130 \mathrm{~min}$ & $76 \mathrm{~min}$ & $31 \mathrm{~min}$ & - \\
\hline Median crossing time & $58 \mathrm{~min}$ & $60 \mathrm{~min}$ & $14 \mathrm{~min}$ & - \\
\hline
\end{tabular}
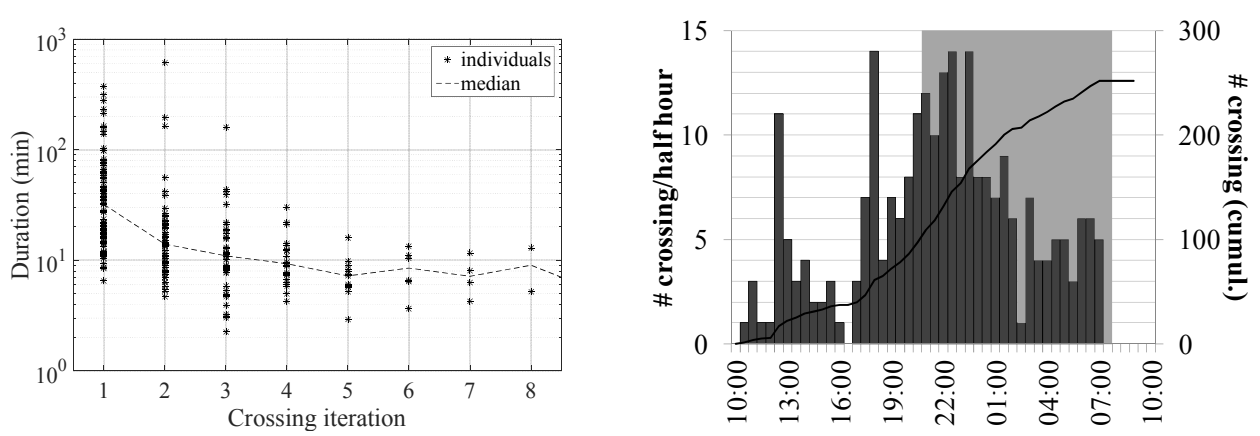

Fig. 2. Chub: (a) Crossing duration for successive crossing by a single individual; (b) Crossing distribution with time and photoperiod.

Lastly, the test performed with all the chub (118 ind.) introduced in the downstream tank, taken as the river with no flow, confirmed that they were attracted and could easily enter the fish pass. During the 4.5 days of the test, $76 \%$ of the chubs entered at least once in the fish pass (by crossing slot S7). It was also found that, when entering the pass, the chub clearly differentiated the flow coming out of slot S7 from the higher flow from the additional discharge channel. Only $20 \%$ of the chub that entered the pass were first detected at the outlet of the additional discharge channel.

\subsection{Trajectories and presence areas}

From the video images, it was possible to identify fish position and trajectories. As a first result, Figure 3 presents a view of the preferred presence areas of the fish. For each image, the centroid of each fish was affected to the nearest pixel. The cumulative times of presence 
were then calculated at each pixel for the whole video sequence available. Red colour corresponds to a presence of up to 30 minutes, while the darkest blue corresponds to a single detection.

For both bleak (Fig. 3a) and chub (Fig. 3b), it is observed that the presence rate is higher around the borders of the pool than in the centre. The highest presence is observed in the dead water zone just downstream the slot (area marked 1). These observations can be correlated with the computed flow pattern depicted on Fig. 3d [4]. The flow velocities are higher in the jet downstream the slot. Presence areas are located in lower velocity areas, where the fish need less energy to remain stable. This observation is obvious for the bullhead (Fig. 3c). They could only remain stable along the bottom of the walls in the absence of bed roughness. Some of them even sheltered behind the sill of the slot and the protruding PIT-tag antenna (area 2). Globally, the observed resting areas are found in accordance with previous studies $[8,9,5]$.

Lastly, some trajectory plots (Figure 4) show how the chub were swimming at ease. Trajectory 1 shows a chub crossing the main recirculation area before escaping to a lateral dead water zone. Trajectory 2 shows a chub swimming for a while against the main flow before moving towards the wall.

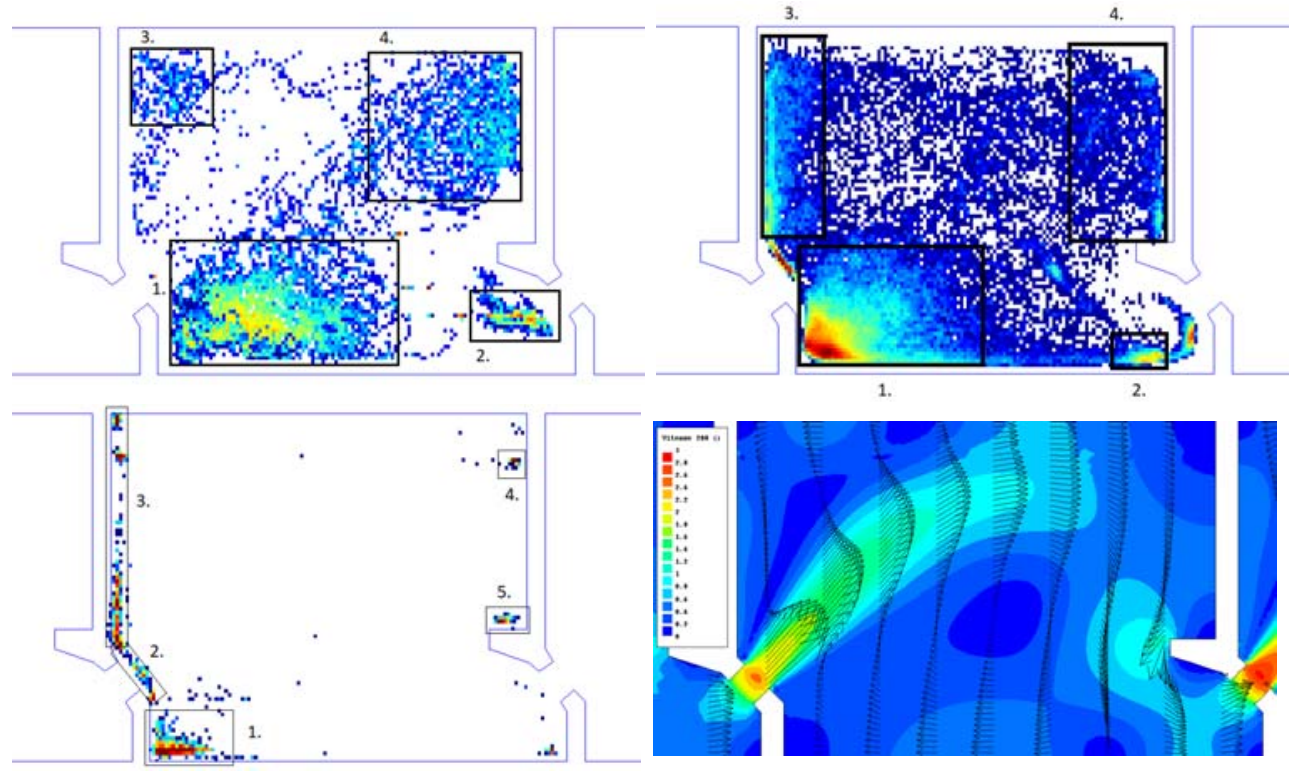

Fig. 3. Pool P1, Presence areas: (a) bleak; (b) chub; and (c) bullhead. (d) Computed flow pattern, velocity from 0 to $3 \mathrm{~m} / \mathrm{s}$ [4].
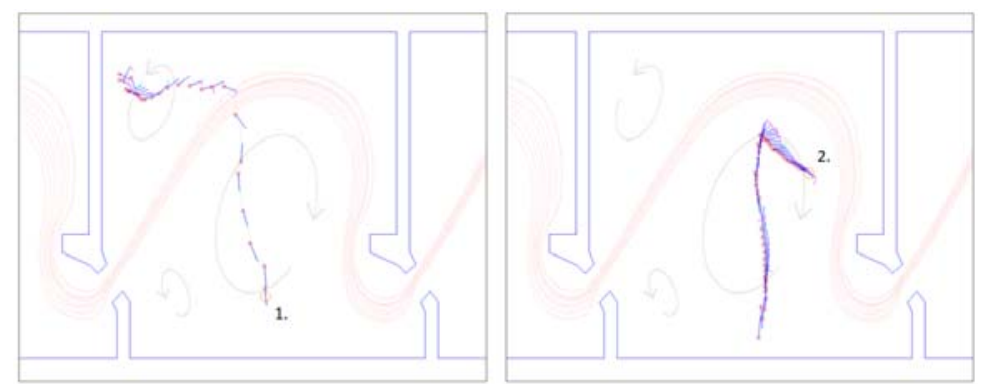

Fig. 4. Chub: typical trajectories. Initial position identified by the reference number. Plot each 1/15 s. 


\section{Conclusions}

Assessing the efficiency of a fish pass for multiple fish species is always challenging. In the present study, a scale model of a vertical slot fish pass was tested with living fish: juvenile farm Atlantic salmon and chub; and captured adult bleak and bullhead. Their ability to cross the whole fish pass was recorded tanks to PIT-tag marking; and their trajectories and presence areas were recorded by video.

Results show that both salmon and chub were at ease in the fish pass, even if the swimming capacity of juveniles in the scale model is estimated to be relatively lower compared to the swimming capacity of adults in the prototype. High mobility was observed for both species, with crossing rate of 30 and $75 \%$, respectively. Bleak was also able to cross the whole pass, with a lower rate of success. Bullhead, as a benthic fish, was hindered by the absence of bed roughness. It could not remain stable in the flow and only the largest adult individuals were able to cross one slot. Further experiments are now planned to investigate the benefits of adding bed roughness elements.

Video recordings show that the preferred presence areas are close to the wall, in lower velocity areas. Trajectories tracking nevertheless highlights the capacity of individuals (notably chub) to remain stable in the main flow.

The authors acknowledge the help of Yvan Neus, technical manager at the Meuse Salmon Conservancy Center in Erezée (Belgium), Fisheries Service of the Service Public de Wallonie, who prepared the fish batches.

\section{References}

1. PIANC. Fish passage. Report 127 (2013)

2. FAO/DVWK. Fish passes - Design, dimensions and monitoring. (FAO, Rome, 2002)

3. M. Larinier, F. Travade, J.P. Porcher. Bulletin français de la Pêche et de la Pisciculture, 364 (2002)

4. D. Bousmar, G. Zorzan, A. Gillet, J. Lopez Delhoulle, A. Baugnée, J.C. De Greef. Proc. River Flow 2014, 2427-2435 (Taylor \& Francis, 2014)

5. D. Bousmar, J.C. Pype, X. Rollin. Proc. River Flow 2016, 2377-2384 (Taylor \& Francis, 2016)

6. E. Aramburu Godinez, F. Morcillo Alonso, M. Castillo Blanco, A. Lara Domínguez. Ingeniería Civil, 173, 33-42 (2014)

7. E. Guiny, D.A. Ervine, D. Armstrong. J. Hydraulic Engrg. 131(7), 542-553 (2005)

8. R.W. Wang, L. David, M. Larinier. Knowl. Managt. Aqu. Ecosyst. 396(2), (2010)

9. V. Cornu, P. Baran, D. Calluaud, L. David. Proc. $9^{\text {th }}$ Int. Symp. Ecohydraulics. Vienna, Austria (2012)

10. B. Kynard, M. Horgan, D. Pugh, E. Henyey, T. Parker. Am. Fisheries Soc. Symp. 61 (2008)

11. C. Prignon, J.C. Micha, A. Gillet. Fish Migration and Fish bypasses. $69-84$ (Fishing News Books-Blackwell Science, Oxford, 1998)

12. G. Zorzan, D. Bousmar, Y. Libert. Final report Mod. 066 (SPW-DO.222, Châtelet, Belgium, 2016)

13. C. Katopodis, R. Gervais. Ichtyomechanics. Freshwater Inst., Central \& Artic Reg., Dept. Fisheries and Ocean (1991)

14. E. Courtois, L. Van Audenhaege. Master thesis. UCL, Belgium (2016) 